\title{
Adult Born Olfactory Bulb Dopaminergic Interneurons: Molecular Determinants and Experience-Dependent Plasticity
}

\author{
Sara Bonzano ${ }^{1,2}$, Serena Bovetti ${ }^{3}$, Claudio Gendusa ${ }^{1}$, Paolo Peretto ${ }^{1,2}$ and \\ Silvia De Marchis ${ }^{1,2 *}$ \\ ${ }^{1}$ Department of Life Sciences and Systems Biology, University of Turin, Torino, Italy, ${ }^{2}$ Neuroscience Institute Cavalieri \\ Ottolenghi, University of Turin, Orbassano, Italy, ${ }^{3}$ Department of Neuroscience and Brain Technologies, Istituto Italiano di \\ Tecnologia, Genova, Italy
}

The olfactory bulb $(\mathrm{OB})$ is a highly plastic brain region involved in the early processing of olfactory information. A remarkably feature of the OB circuits in rodents is the constitutive integration of new neurons that takes place during adulthood. Newborn cells in the adult $\mathrm{OB}$ are mostly inhibitory interneurons belonging to chemically, morphologically and functionally heterogeneous types. Although there is general agreement that adult neurogenesis in the $\mathrm{OB}$ plays a key role in sensory information processing and olfaction-related plasticity, the contribution of each interneuron subtype to such functions is far to be elucidated. Here, we focus on the dopaminergic (DA) interneurons: we highlight recent findings about their morphological features and then describe the molecular factors required for the specification/differentiation and maintenance of the DA phenotype in adult born neurons. We also discuss dynamic changes of the DA interneuron population related to age, environmental stimuli and lesions, and their possible functional implications.

Keywords: olfactory bulb, dopaminergic neurons, tyrosine hydroxylase, adult neurogenesis, COUP-TFI, juxtaglomerular neurons, odor enrichment, odor deprivation

\section{INTRODUCTION}

In mammals, dopaminergic (DA) neurons are classified in distinct neuronal cell groups (from A8 to A16) based on their substantial diversity (Björklund and Dunnett, 2007). DA neurons in the olfactory bulb (OB) belong to the A16 group and represent the major DA system in the forebrain (Cave and Baker, 2009). Olfactory DA cells are reliably identified by the expression of tyrosine hydroxylase $(\mathrm{TH})$, the rate-limiting enzyme of catecholamine biosynthesis, since they represent the only catecholaminergic cell type found in the OB (Cave and Baker, 2009). THpositive cells are mostly localized in the OB glomerular cell layer (GL; Figure 1A), where they account for nearly $10 \%$ of all juxtaglomerular cells (JGCs; Parrish-Aungst et al., 2007). THpositive JGCs express glutamic acid decarboxylase (GAD), the rate-limiting enzyme for GABA biosynthesis, and co-release dopamine and GABA on their post-synaptic targets (Liu et al., 2013). Their electrophysiological properties have been extensively characterized (Pignatelli et al., 2005, 2009, 2013; Borin et al., 2014). TH-positive cells establish synaptic contacts with the afferent olfactory receptor neuron terminals and/or with external tufted cells and form extensive 

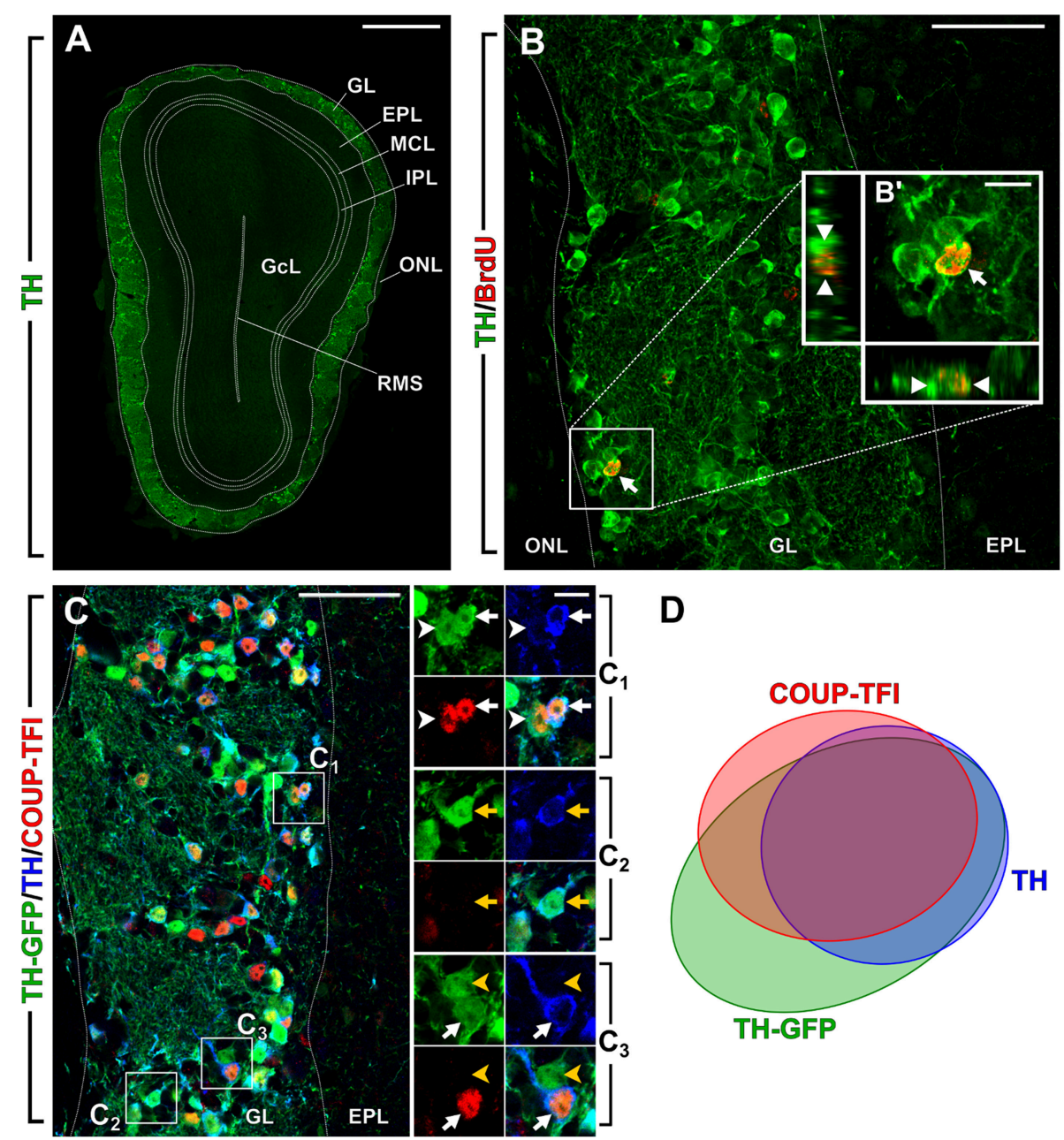

D

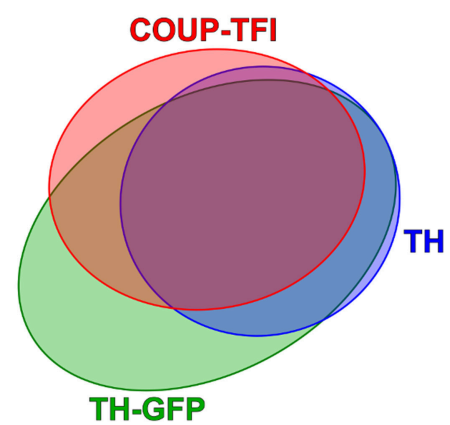

FIGURE 1 | Olfactory bulb dopaminergic interneurons. New image from previously published experiments (Bovetti et al., 2013; Bonzano et al., 2014). (A) Photomicrograph showing a coronal section of the olfactory bulb $(\mathrm{OB})$ in a 2-month-old wild-type mouse. DA cells immunopositive for TH (green) are mostly confined within the OB glomerular layer (GL). (B) BrdU-positive adult born DA cell (arrow) in a representative confocal image of the OB GL double-stained for BrdU (red) and TH (green) in a mouse that received BrdU at 2 months of age and analyzed 42 days after. $\mathrm{B}^{\prime}$ shows higher magnification and re-slicing of the BrdU/TH double positive cell. (C) Multiple labeling of the OB GL in a 2-month-old TH-GFP transgenic mouse line (Sawamoto et al., 2001). GFP (green) is expressed under the control of TH promoter; TH-immunopositive cells are shown in blue and COUP-TFI immunopositive nuclei in red. C1 shows higher magnification of a cell that is triple labeled for GFP/TH/COUP-TFI (white arrow) and a cell that is double labeled for GFP and COUP-TFI (white arrowhead). C2 shows higher magnification of a cell that is double labeled for GFP and TH (yellow arrow). C3 shows a cell that is triple labeled for GFP/TH/COUP-TFI (white arrow) and a cell that is GFP-positive only (yellow arrowhead). (D) Venn diagram showing the overlap of the labeling for TH-GFP, TH and COUP-TFI immunoreactivity based on our previously published data (Bovetti et al., 2013). A fraction of TH-GFP positive cells is negative for both TH and COUP-TFI. As previously reported these cells are likely immature DA neurons not expressing yet TH protein (Pignatelli et al., 2009). There is a high overlap between TH-GFP/TH/COUP-TFI labeling indicating that COUP-TFI expression is tightly associated with the DA phenotype. Scale bar in A $=500 \mu \mathrm{m}$. Scale bar in B and C =50 $\mu \mathrm{m}$. Scale bar in inset $\mathrm{B}^{\prime}=10 \mu \mathrm{m}$. Scale bar in inset $\mathrm{C} 1=10 \mu \mathrm{m}$ and refers to $\mathrm{C} 2$ and $\mathrm{C} 3$. ONL, olfactory nerve layer; GL, glomerular layer; EPL, external plexiform layer; MCL, mitral cell layer; IPL, internal plexiform layer; GcL, granule cell layer; RMS, rostral migratory stream of the OB.

interglomerular connections (Kiyokage et al., 2010; Kosaka and Kosaka, 2011), participating to the early steps in odor information processing that occur in the input layer of the OB. Accordingly, a recent study demonstrated a key function for DA cells in implementing gain control and reducing correlation of odor representations in the main output neurons (i.e., mitral/tufted cells) (Banerjee et al., 2015). In line with a central role for DA cells in the encoding of odor stimuli, several studies support the impact of the DA system in fundamental features of odor-driven behaviors (Kruzich and Grandy, 2004; Pavlis et al., 2006; Tillerson et al., 2006; Wei et al., 2006; Serguera et al., 2008; Lazarini et al., 2014). Moreover, olfactory dysfunction is associated to pathological states affecting the DA system, such as in Parkinson disease (Doty, 2012). Although olfactory dysfunction in PD patients could also involve OB DA cells, recent data in rodents indicate this is mostly attributable to depletion in the DA nigro-olfactory projection system (Höglinger et al., 2015). 
Olfactory DA neurons have attracted significant attention over the years, because they are involved in substantial activitydependent plasticity, regulating the level of $\mathrm{TH}$ expression and dopamine release according to the sensory input (Nadi et al., 1981; Baker et al., 1983, 1984; Cummings et al., 1997). Moreover, DA cells are constantly generated throughout life and recent reports pointed to a specific integration of this juxtaglomerular cell population in the GL circuits in an activity-dependent manner (Sawada et al., 2011; Bonzano et al., 2014). Because of their continuous generation throughout life, DA cells are also regarded as a potential target to exploit adult neurogenesis for dopamine system repair in the brain (see Cave et al., 2014). Here we focused on emerging aspects related to DA cells heterogeneity, molecular determinants of adult born DA neurons, their plasticity and function in the OB.

\section{OLFACTORY DA INTERNEURONS BELONG TO TWO MAIN MORPHOLOGICALLY DISTINCT CELL POPULATIONS}

The view that DA cells in the $\mathrm{OB}$ consist of distinct types emerged many years ago from the immunohistochemical identification of two different categories of $\mathrm{TH}$-positive neurons in the rat and mouse OB (Halász et al., 1981; Baker et al., 1983; McLean and Shipley, 1988). Based on their soma size and location, TH-positive cells were initially classified either as small periglomerular cells (PG, soma diameter about 5-10 $\mu \mathrm{m}$ ), positioned in the GL and representing the large majority of olfactory DA cells, or large external tufted cells (ET, soma diameter about 10-15 $\mu \mathrm{m}$ ), positioned mostly at the boundary between the GL and the external plexiform layer (EPL) and rarely found within the EPL. Interestingly, DA cells belonging to the larger type are born earlier during development than the smaller ones (McLean and Shipley, 1988), possibly from local OB progenitors in the E13.5 mouse embryo (VergañoVera et al., 2006), before precursors from the main germinal niches for OB interneurons (i.e., LGE, pallium, and septum) start to populate the $\mathrm{OB}$ and differentiate into multiple interneuron subtypes (Bovetti et al., 2007; Alvarez-Buylla et al., 2008). Furthermore, Kosaka and Kosaka (2009) showed that adult subventricular zone (SVZ) progenitors do not contribute to the generation of the larger type of DA cells, indicating this population does not undergo the neuronal turnover typical of most GL interneurons, including small-medium sized DA cells (Bovetti et al., 2009).

Morphometric investigation of $\mathrm{TH}$-positive neuronal projection in the GL has successively revealed that DA cells extend processes into multiple glomeruli (Kosaka and Kosaka, 2008; Kiyokage et al., 2010), suggesting that they should be more appropriately classified as short-axon (SA) cells instead of PG and ET cells, whose processes are mostly confined to one single glomerulus (Pinching and Powell, 1971; Kiyokage et al., 2010). Importantly, Kiyokage et al. (2010) described two distinct types of SA TH-positive cells, oligoglomerular and polyglomerular, based on their process extension and average number of contacted glomeruli. The vast majority of DA cells falls within the first category (i.e., oligoglomerular), having processes spanning a relatively short region of the GL and contacting in average nearly 6 glomeruli. Polyglomerular cells show more extensive projections, contact in average nearly 40 glomeruli and are likely to correspond to the large DA cells previously described to establish long-range interglomerular connections by Kosaka and Kosaka (2008). An additional feature that allows differentiating distinct types of olfactory DA cells is the presence/absence of an axon. Both in vivo (Kosaka and Kosaka, 2011) and in vitro (Chand et al., 2015) studies clearly indicated that larger DA cells possess an axon initial segment (AIS), reminiscent of an axonal process, while the other, smaller in size do not.

Overall, most evidences point to the existence of two main morphologically and possibly functionally separate populations of olfactory DA cells, of which only one (i.e., small/mediumsized DA neurons) undergoes continuous neurogenesis during adulthood (Figure 1B).

\section{MOLECULAR DETERMINANTS OF THE DA PHENOTYPE IN THE ADULT OLFACTORY BULB}

The generation of $\mathrm{OB}$ interneuron subtypes has been demonstrated to depend on a transcriptional code that is regulated in a spatio-temporal manner (Bovetti et al., 2007; Alvarez-Buylla et al., 2008). Distinct progenitor lineages differentially contribute to the generation of TH-positive cells during development or in adult mice. By means of genetic fate mapping Kohwi et al. demonstrated that while in neonates OB TH-positive cells only marginally (4\%) derive from Emx1expressing pallial progenitors, in adult age $42 \%$ of $\mathrm{TH}$-positive $\mathrm{OB}$ interneurons are derived from this lineage (Kohwi et al., 2007). A prominent pallial origin of postnatal/adult DA interneurons is further supported by data obtained through adenoviral-mediated labeling of regionally restricted radial glial stem cells, showing that $\mathrm{TH}$-positive neurons largely derive from progenitors located in the dorsal portion of the SVZ (Merkle et al., 2007). Several transcription factors (TFs), namely Pax6, Dlx2, Id2, Klf7, ER81, Sall3, Nurr1, and Meis2 (Saino-Saito et al., 2004, 2007; Hack et al., 2005; Kohwi et al., 2005; Brill et al., 2008; Havrda et al., 2008; Cave et al., 2010; Caiazzo et al., 2011; Heng et al., 2012; Agoston et al., 2014; Vergaño-Vera et al., 2015) have been shown to be required for proper differentiation of olfactory DA neurons. Here we will limit the review to those TFs whose function in the control of olfactory DA fate has been directly demonstrated in adult born neurons (Table 1). Among these, Pax6 and Dlx2 play a major role (Hack et al., 2005; Kohwi et al., 2005; Brill et al., 2008; de Chevigny et al., 2012). The use of retroviral-mediated overexpression of Dlx2 in neuronal precursors along the rostral migratory stream (RMS) provided data supporting a cell-autonomous role for this TF in promoting specification of adult born neurons toward DA fate (Brill et al., 2008). Similar results, implying increased generation of DA interneurons, were previously described by over-expressing the TF Pax6 in adult neuronal precursors 
TABLE 1 | Transcription factors involved in the control of adult born olfactory DA fate specification and maintenance.

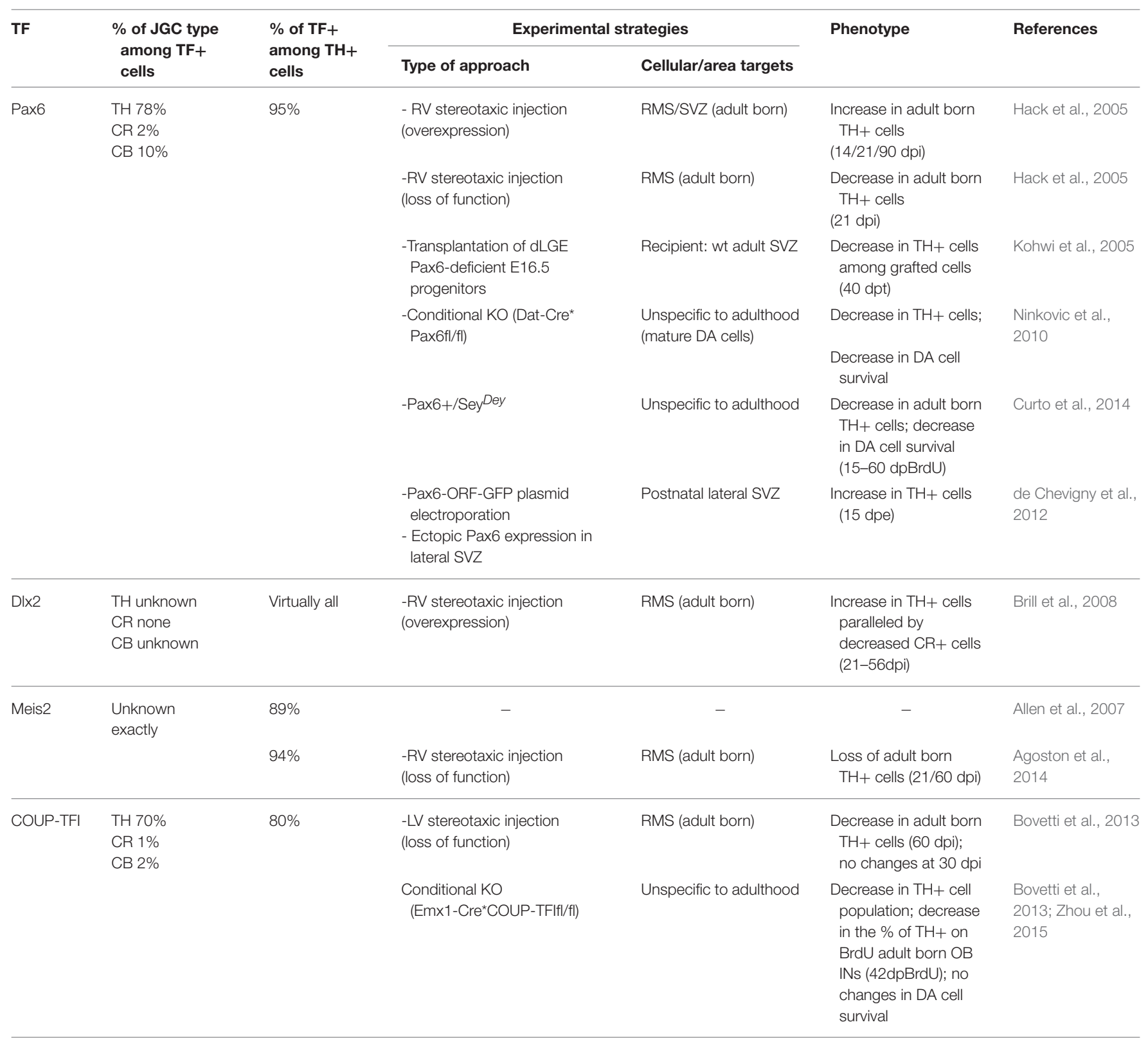

TH, tyrosine hydroxylase; TF, transcription factor; CR, calretinin; CB, calbindin; dpi, day(s) post injection; dpBrdU, day(s) post BrdU injection(s); dpe, day(s) post electroporation; dpt, day(s) post transplantation; RV, Retroviral vector; LV, Lentiviral vector; RMS, Rostral Migratory Stream; SVZ, Sub Ventricular Zone; dLGE, dorsal Lateral Ganglionic Eminence.

migrating along the RMS (Hack et al., 2005). In addition, by increasing Pax6 protein level in the lateral wall, where normally Pax6 protein is absent due to post-transcriptional inhibition by mir-7a, the acquisition of the DA phenotype in the OB is favored (de Chevigny et al., 2012). Moreover, the effect of Dlx2 overexpression is totally abrogated in the absence of Pax6 and functional direct interaction/cooperation between Dlx2 and Pax6 is needed to instruct DA fate in adult mice (Brill et al., 2008). A critical co-factor for Pax6 and Dxl2 function in exploiting DA fate commitment in adult born $\mathrm{OB}$ interneurons has been recently identified in Meis2, a member of the three amino acid loop extension class of atypical homeodomain-containing transcription factors (Agoston et al., 2014). Meis2, together with Pax6 and Dlx2, is needed to determine the differentiation toward a DA phenotype over the CR one by directly interacting with TH regulatory sequences (Agoston et al., 2014). Besides the instructive role for Pax6 in DA fate commitment in OB interneuron precursors, Pax6 is also critically involved in OB DA cell maintenance. Indeed, by conditionally deleting Pax6 in mature DA cells Ninkovic et al. (2010) identified Pax6 as a positive controller of mature DA cell survival through the positive regulation of crystallin $\alpha \mathrm{A}$ in the adult $\mathrm{OB}$. 
Recently, we have identified a distinct, yet central, role in the maintenance of the DA phenotype of adult born OB interneurons for the orphan nuclear receptor COUP-TFI (Bovetti et al., 2013). Among juxtaglomerular interneurons in the adult mouse OB, COUP-TFI expression is exclusively found in DA cells, with nearly $80 \%$ of mature TH-positive cells (Figures 1C,D) and $90 \%$ of Pax6-positive cells double positive for COUP-TFI. Interestingly, the expression of COUP-TFI is mostly confined to DA cells generated during late postnatal/adult life, and is regulated by the sensory input. Indeed, odor deprivation through naris occlusion induces COUP-TFI down-regulation jointly with TH down-regulation in olfactory DA cells. Moreover, we observed a net impairment in $\mathrm{TH}$ expression in fully mature cells following ablation of COUP-TFI function in either a) DA interneuron progenitors by means of conditional COUP-TFI deletion in the Emx1-lineage or b) post-mitotic adult born neurons by lentiviral-mediated approach in vivo (Bovetti et al., 2013). These findings strongly indicate a role for COUP-TFI in $\mathrm{TH}$ expression regulation, as also recently confirmed by another study (Zhou et al., 2015). Importantly, COUP-TFI ablation on DA cells does not affect the acquisition and maturation of the DA phenotype, but impairs immediate early gene expression (i.e., egr-1; Bovetti et al., 2013). Overall, these data, together with the apparent lack of consensus binding sites for COUP-TFI on the $\mathrm{TH}$ promoter, strongly indicate that COUP-TFI regulates $\mathrm{TH}$ expression in $\mathrm{OB}$ cells through an activity-dependent mechanism involving immediate early gene induction and strongly argue for a maintenance rather than establishment function of COUPTFI in the DA commitment. Thus, besides the role of TFs such as Pax6, Meis2, and Dlx2 that are directly involved in OB DA fate determination within adult SVZ neural stem cell/precursors, COUP-TFI must be part of a distinct transcription factor program that is central for the maintenance of the DA cell identity over time.

\section{EXPERIENCE-DEPENDENT PLASTICITY OF OLFACTORY DA NEURONS: A DUAL MECHANISM INVOLVING TH-EXPRESSION REGULATION AND ADULT NEUROGENESIS}

Several lines of evidence support the notion that olfactory DA neurons are unique among OB neurons, being particularly susceptible to sensory stimuli. A first level of experiencedependent plasticity of DA cells consists in the regulation of $\mathrm{TH}$ expression and consequently dopamine production/release, according to the sensory input. Indeed, $\mathrm{TH}$ expression in DA cells is strongly and reversibly down-regulated in animals subjected to odor deprivation by either chemical or surgical sensory deafferentation of the OB (Nadi et al., 1981; Kawano and Margolis, 1982; Baker et al., 1983), or naris occlusion (Baker et al., 1993). This effect does not seem to be restricted to a specific DA cell population (see above; Baker et al., 1983) and applies to both pre-existing and adult generated neurons (Bovetti et al., 2009; Bastien-Dionne et al., 2010). In parallel to $\mathrm{TH}$ down-regulation, odor deprivation also induces downregulation of GAD67, which is selectively co-expressed by DA cells, but not of GAD65, which is mainly expressed by other juxtaglomerular cell types (Parrish-Aungst et al., 2011). Although the view that olfactory DA neurons are exposed to modulation of their transmitter phenotype by the olfactory input has long been recognized (Baker et al., 1983, 1984; McLean and Shipley, 1988), the molecular mechanisms underlying this phenomenon are just beginning to emerge. A direct link among the expression of immediate early genes, increased neuronal activity and $\mathrm{TH}$ expression in the GL has been previously hypothesized (Jin et al., 1996). As reported above, we recently identified a role for DA cell responsiveness to sensory stimuli for COUP-TFI, whose depletion in adult generated DA cells induces both reduced immediate early gene and $\mathrm{TH}$ expression (Bovetti et al., 2013). Moreover, recent studies highlighted the involvement of epigenetic regulatory mechanisms in the activitydependent modulation of the neurotransmitter phenotype in OB interneurons (Banerjee et al., 2013).

Besides $\mathrm{TH}$ expression regulation, sensory activity can significantly impact on the composition of the DA population through modulation of adult neurogenesis. Indeed, manipulation of the sensory input by either odor deprivation or enrichment elicits, respectively, decreased or increased survival of adult generated juxtaglomerular interneurons (Bovetti et al., 2009), as previously demonstrated for granule cells (Rochefort et al., 2002; Mandairon et al., 2006). Increasing evidence points to DA cells as a selective cellular target for sensory-dependent modulation of adult neurogenesis in the GL of the $\mathrm{OB}$. Using a paradigm of naris occlusion in adult mice, Sawada et al. (2011) found that among different neurochemical types of juxtaglomerular cells, THpositive DA cells were the only one to show increased apoptosis. Interestingly, mice in which the naris was reopened showed increased integration of new DA cells after a 4 weeks recovery phase that compensate for the selective loss of DA cells due to previous deprivation. A restorative role of adult neurogenesis has been also demonstrated in another experimental paradigm in which a selective DA neuronal loss, induced by local treatment with 6-hydroxydopamine (6-OHDA) in the dorsal OB, was followed by a full recovery of DA cells (Lazarini et al., 2014). Regulation of DA cell generation in adulthood is not limited to restorative conditions but occurs also in basal physiological condition and in response to sensory enrichment. Interestingly, a net and selective increase in the glomerular DA population with age has been reported in a long term two-photon imaging study in vivo (Adam and Mizrahi, 2011). Although the meaning of these age-dependent changes in the DA population is unknown, these data reinforce the idea that a certain plasticity of the DA population is required for $\mathrm{OB}$ circuit functions. In a recent study from our group (Bonzano et al., 2014), a paradigm of prolonged ( 2 months) olfactory enrichment with different aromatic fragrances, which has been previously shown to affect OB neurogenesis (Rochefort et al., 2002; Bovetti et al., 2009) and olfactory memory (Rochefort et al., 2002), resulted in a selective increase in the TH-positive DA population, due to increased neurogenesis, without changes in calretinin (CR)- and calbindin (CB)-positive neurons (Bonzano et al., 2014). These 
results further support that adult neurogenesis does not reflect a simple turnover of the whole GL interneuron population, but it can finely modulate specific $\mathrm{OB}$ neuron subpopulations (i.e., DA cells) with particular functions in odor processing.

\section{CONCLUSION AND FUTURE PERSPECTIVE}

In the adult $\mathrm{OB}, \mathrm{DA}$ cells are unique in term of their plasticity in response to sensory inputs. Although their involvement in mechanisms underlying the adaptation of the olfactory system to changes in sensory experience is well established, many aspects remain still unknown. The heterogeneity of DA cell population in term of morphology, connections (Kosaka and Kosaka, 2008; Kiyokage et al., 2010; Chand et al., 2015), origin (McLean and Shipley, 1988; Vergaño-Vera et al., 2006; De Marchis et al., 2007; Kohwi et al., 2007; Merkle et al., 2007) and renewal (Kosaka and Kosaka, 2009) further complicate the understanding of DA cell role in odor coding, processing and plasticity. New molecular and optical approaches able to selectively target adult born DA interneurons will hopefully bring new insights in unraveling their role in olfactory physiology. The precise in vivo readout of cell

\section{REFERENCES}

Adam, Y., and Mizrahi, A. (2011). Long-term imaging reveals dynamic changes in the neuronal composition of the glomerular layer. J. Neurosci. 31, 7967-7973. doi: 10.1523/JNEUROSCI.0782-11.2011

Agoston, Z., Heine, P., Brill, M. S., Grebbin, B. M., Hau, A.-C., KallenbornGerhardt, W., et al. (2014). Meis2 is a Pax6 co-factor in neurogenesis and dopaminergic periglomerular fate specification in the adult olfactory bulb. Development 141, 28-38. doi: 10.1242/dev.097295

Akemann, W., Mutoh, H., Perron, A., Rossier, J., and Knöpfel, T. (2010). Imaging brain electric signals with genetically targeted voltage-sensitive fluorescent proteins. Nat. Methods 7, 643-649. doi: 10.1038/nmeth.1479

Allen, Z. J., Waclaw, R. R., Colbert, M. C., and Campbell, K. (2007). Molecular identity of olfactory bulb interneurons: transcriptional codes of periglomerular neuron subtypes. J. Mol. Histol. 38, 517-525. doi: 10.1007/s10735-007-9115-4

Alvarez-Buylla, A., Kohwi, M., Nguyen, T. M., and Merkle, F. T. (2008). The heterogeneity of adult neural stem cells and the emerging complexity of their niche. Cold Spring Harb. Symp. Quant. Biol. 73, 357-365. doi: 10.1101/sqb.2008.73.019

Baker, H., Kawano, T., Albert, V., Joh, T. H., Reis, D. J., and Margolis, F. L. (1984). Olfactory bulb dopamine neurons survive deafferentation-induced loss of tyrosine hydroxylase. Neuroscience 11, 605-615. doi: 10.1016/03064522(84)90047-2

Baker, H., Kawano, T., Margolis, F. L., and Joh, T. H. (1983). Transneuronal regulation of tyrosine hydroxylase expression in olfactory bulb of mouse and rat. J. Neurosci. 3, 69-78.

Baker, H., Morel, K., Stone, D. M., and Maruniak, J. A. (1993). Adult naris closure profoundly reduces tyrosine hydroxylase expression in mouse olfactory bulb. Brain Res. 614, 109-116. doi: 10.1016/0006-8993(93)91023-L

Banerjee, A., Marbach, F., Anselmi, F., Koh, M. S., Davis, M. B., Garcia da Silva, P., et al. (2015). An interglomerular circuit gates glomerular output and implements gain control in the mouse olfactory bulb. Neuron 87, 193-207. doi: 10.1016/j.neuron.2015.06.019

Banerjee, K., Akiba, Y., Baker, H., and Cave, J. W. (2013). Epigenetic control of neurotransmitter expression in olfactory bulb interneurons. Int. J. Dev. Neurosci. 31, 415-423. doi: 10.1016/j.ijdevneu.2012.11.009 activity now possible exploiting the last generation of calcium and voltage indicators (Akemann et al., 2010; Chen et al., 2013; Gong et al., 2015), combined with the capability to selectively manipulate cell activity through optogenetic and chemogenetic tools (Boyden et al., 2005; Deisseroth et al., 2006; Liu et al., 2013; Sternson and Roth, 2014), are the straightforward direction toward the complete dissection of glomerular network function and adult born DA cell role in activity-dependent plasticity. Nonetheless, new molecular and genetic tools may contribute to further clarify and reach a final consensus on olfactory DA cell classification.

\section{AUTHOR CONTRIBUTIONS}

All authors listed, have made substantial, direct, and intellectual contribution to the work, and approved its final version for publication.

\section{FUNDING}

This work was supported by the University of Turin (ex $60 \%$ 2014-2015 to SDM).

Bastien-Dionne, P. O., David, L. S., Parent, A., and Saghatelyan, A. (2010). Role of sensory activity on chemospecific populations of interneurons in the adult olfactory bulb. J. Comp. Neurol. 518, 1847-1861. doi: 10.1002/cne.22307

Björklund, A., and Dunnett, S. B. (2007). Dopamine neuron systems in the brain: an update. Trends Neurosci. 30, 194-202. doi: 10.1016/j.tins.2007.03.006

Bonzano, S., Bovetti, S., Fasolo, A., Peretto, P., and De Marchis, S. (2014). Odour enrichment increases adult-born dopaminergic neurons in the mouse olfactory bulb. Eur. J. Neurosci. 40, 3450-3457. doi: 10.1111/ejn.12724

Borin, M., Fogli Iseppe, A., Pignatelli, A., and Belluzzi, O. (2014). Inward rectifier potassium (Kir) current in dopaminergic periglomerular neurons of the mouse olfactory bulb. Front. Cell. Neurosci. 8:223. doi: 10.3389/fncel.2014.00223

Bovetti, S., Bonzano, S., Garzotto, D., Giannelli, S. G., Iannielli, A., Armentano, M., et al. (2013). COUP-TFI controls activity-dependent tyrosine hydroxylase expression in adult dopaminergic olfactory bulb interneurons. Development 140, 4850-4859. doi: 10.1242/dev.089961

Bovetti, S., Peretto, P., Fasolo, A., and De Marchis, S. (2007). Spatio-temporal specification of olfactory bulb interneurons. J. Mol. Histol. 38, 563-569. doi: 10.1007/s10735-007-9111-8

Bovetti, S., Veyrac, A., Peretto, P., Fasolo, A., and De Marchis, S. (2009). Olfactory enrichment influences adult neurogenesis modulating GAD67 and plasticityrelated molecules expression in newborn cells of the olfactory bulb. PLOS ONE 4:e6359. doi: 10.1371/journal.pone.0006359

Boyden, E. S., Zhang, F., Bamberg, E., Nagel, G., and Deisseroth, K. (2005). Millisecond-timescale, genetically targeted optical control of neural activity. Nat. Neurosci. 8, 1263-1268. doi: 10.1038/nn1525

Brill, M. S., Snapyan, M., Wohlfrom, H., Ninkovic, J., Jawerka, M., Mastick, G. S., et al. (2008). A Dlx2- and Pax6-Dependent transcriptional code for periglomerular neuron specification in the adult olfactory bulb. J. Neurosci. 28, 6439-6452. doi: 10.1523/JNEUROSCI.0700-08.2008

Caiazzo, M., Colucci-D'Amato, L., Volpicelli, F., Speranza, L., Petrone, C., Pastore, L., et al. (2011). Kruppel-like factor 7 is required for olfactory bulb dopaminergic neuron development. Exp. Cell Res. 317, 464-473. doi: 10.1016/j.yexcr.2010.11.006

Cave, J. W., Akiba, Y., Banerjee, K., Bhosle, S., Berlin, R., and Baker, H. (2010). Differential regulation of dopaminergic gene expression by Er81. J. Neurosci. 30, 4717-4724. doi: 10.1523/JNEUROSCI.0419-10.2010 
Cave, J. W., and Baker, H. (2009). Dopamine systems in the forebrain. Adv. Exp. Med. Biol. 651, 15-35. doi: 10.1007/978-1-4419-0322-8_2

Cave, J. W., Wang, M., and Baker, H. (2014). Adult subventricular zone neural stem cells as a potential source of dopaminergic replacement neurons. Front. Neurosci. 8:16. doi: 10.3389/fnins.2014.00016

Chand, A. N., Galliano, E., Chesters, R. A., and Grubb, M. S. (2015). A distinct subtype of dopaminergic interneuron displays inverted structural plasticity at the axon initial segment. J. Neurosci. 35, 1573-1590. doi: 10.1523/JNEUROSCI.3515-14.2015

Chen, T.-W., Wardill, T. J., Sun, Y., Pulver, S. R., Renninger, S. L., Baohan, A., et al. (2013). Ultrasensitive fluorescent proteins for imaging neuronal activity. Nature 499, 295-300. doi: 10.1038/nature12354

Cummings, D. M., Henning, H. E., and Brunjes, P. C. (1997). Olfactory bulb recovery after early sensory deprivation. J. Neurosci. 17, 7433-7440.

Curto, G. G., Nieto-Estévez, V., Hurtado-Chong, A., Valero, J., Gómez, C., Alonso, J. R., et al. (2014). Pax6 is essential for the maintenance and multi-lineage differentiation of neural stem cells, and for neuronal incorporation into the adult olfactory bulb. Stem Cells Dev. 23, 1-61. doi: 10.1089/scd.2014.0058

de Chevigny, A., Coré, N., Follert, P., Gaudin, M., Barbry, P., Béclin, C., et al. (2012). miR-7a regulation of Pax6 controls spatial origin of forebrain dopaminergic neurons. Nat. Neurosci. 15, 1120-1126. doi: 10.1038/nn.3142

Deisseroth, K., Feng, G., Majewska, A. K., Miesenbock, G., Ting, A., and Schnitzer, M. J. (2006). Next-generation optical technologies for illuminating genetically targeted brain circuits. J. Neurosci. 26, 10380-10386. doi: 10.1523/JNEUROSCI.3863-06.2006

De Marchis, S., Bovetti, S., Carletti, B., Hsieh, Y.-C., Garzotto, D., Peretto, P., et al. (2007). Generation of distinct types of periglomerular olfactory bulb interneurons during development and in adult mice: implication for intrinsic properties of the subventricular zone progenitor population. J. Neurosci. 27, 657-664. doi: 10.1523/JNEUROSCI.2870-06.2007

Doty, R. L. (2012). Olfactory dysfunction in Parkinson disease. Nat. Rev. Neurol. 8 , 329-339. doi: 10.1038/nrneurol.2012.80

Gong, Y., Huang, C., Li, J. Z., Grewe, B. F., Zhang, Y., Eismann, S., et al. (2015). High-speed recording of neural spikes in awake mice and flies with a fluorescent voltage sensor. Sciencexpress 350, 1-11. doi: 10.1126/science.a ab0810

Hack, M. A., Saghatelyan, A., de Chevigny, A., Pfeifer, A., Ashery-Padan, R., Lledo, P.-M., et al. (2005). Neuronal fate determinants of adult olfactory bulb neurogenesis. Nat. Neurosci. 8, 865-872. doi: 10.1038/nn1479

Halász, N., Johansson, O., Hökfelt, T., Ljungdahl, A., and Goldstein, M. (1981). Immunohistochemical identification of two types of dopamine neuron in the rat olfactory bulb as seen by serial sectioning. J. Neurocytol. 10, 251-259. doi: 10.1007/BF01257970

Havrda, M. C., Harris, B. T., Mantani, A., Ward, N. M., Paolella, B. R., Cuzon, V. C., et al. (2008). Id2 is required for specification of dopaminergic neurons during adult olfactory neurogenesis. J. Neurosci. 28, 14074-14087. doi: 10.1523/JNEUROSCI.3188-08.2008

Heng, X., Breer, H., Zhang, X., Tang, Y., Li, J., Zhang, S., et al. (2012). Sall3 correlates with the expression of TH in mouse olfactory bulb. J. Mol. Neurosci. 46, 293-302. doi: 10.1007/s12031-011-9563-x

Höglinger, G. U., Alvarez-Fischer, D., Arias-Carrión, O., Djufri, M., Windolph, A., Keber, U., et al. (2015). A new dopaminergic nigro-olfactory projection. Acta Neuropathol. 130, 333-348. doi: 10.1007/s00401-015-1451-y

Jin, B. K., Franzen, L., and Baker, H. (1996). Regulation of c-Fos mRNA and fos protein expression in olfactory bulbs from unilaterally odor-deprived adult mice. Int. J. Devl. Neurosci. 14, 971-982. doi: 10.1016/S0736-5748(96)00044-5

Kawano, T., and Margolis, F. L. (1982). Transsynaptic regulation of olfactory bulb catecholamines in mice and rats. J. Neurochem. 39, 342-348. doi: 10.1111/j.1471-4159.1982.tb03953.x

Kiyokage, E., Pan, Y.-Z., Shao, Z., Kobayashi, K., Szabo, G., Yanagawa, Y., et al. (2010). Molecular identity of periglomerular and short axon cells. J. Neurosci. 30, 1185-1196. doi: 10.1523/JNEUROSCI.3497-09.2010

Kohwi, M., Osumi, N., Rubenstein, J. L. R., and Alvarez-Buylla, A. (2005). Pax6 is required for making specific subpopulations of granule and periglomerular neurons in the olfactory bulb. J. Neurosci. 25, 6997-7003. doi: 10.1523/JNEUROSCI.1435-05.2005

Kohwi, M., Petryniak, M. A., Long, J. E., Ekker, M., Obata, K., Yanagawa, Y., et al. (2007). A subpopulation of olfactory bulb GABAergic interneurons is derived from Emx1- and Dlx5/6-expressing progenitors. J. Neurosci. 27, 6878-6891. doi: 10.1523/JNEUROSCI.0254-07.2007

Kosaka, T., and Kosaka, K. (2008). Tyrosine hydroxylase-positive GABAergic juxtaglomerular neurons are the main source of the interglomerular connections in the mouse main olfactory bulb. Neurosci. Res. 60, 349-354. doi: 10.1016/j.neures.2007.11.012

Kosaka, T., and Kosaka, K. (2009). Two types of tyrosine hydroxylase positive GABAergic juxtaglomerular neurons in the mouse main olfactory bulb are different in their time of origin. Neurosci. Res. 64, 436-441. doi: 10.1016/j.neures.2009.04.018

Kosaka, T., and Kosaka, K. (2011). "Interneurons" in the olfactory bulb revisited. Neurosci. Res. 69, 93-99. doi: 10.1016/j.neures.2010.10.002

Kruzich, P. J., and Grandy, D. K. (2004). Dopamine D2 receptors mediate two-odor discrimination and reversal learning in C57BL/6 mice. BMC Neurosci. 5:12. doi: 10.1186/1471-2202-5-12

Lazarini, F., Gabellec, M.-M., Moigneu, C., de Chaumont, F., Olivo-Marin, J.-C., and Lledo, P.-M. (2014). Adult neurogenesis restores dopaminergic neuronal loss in the olfactory bulb. J. Neurosci. 34, 14430-14442. doi: 10.1523/JNEUROSCI.5366-13.2014

Liu, S., Plachez, C., Shao, Z., Puche, A., and Shipley, M. T. (2013). Olfactory bulb short axon cell release of GABA and dopamine produces a temporally biphasic inhibition-excitation response in external tufted cells. J. Neurosci. 33, 2916-2926. doi: 10.1523/JNEUROSCI.3607-12.2013

Mandairon, N., Sacquet, J., Jourdan, F., and Didier, A. (2006). Long-term fate and distribution of newborn cells in the adult mouse olfactory bulb: influences of olfactory deprivation. Neuroscience 141, 443-451. doi: 10.1016/j.neuroscience.2006.03.066

McLean, J. H., and Shipley, M. T. (1988). Postmigrational olfactory bulb dopaminergic expression neurons of tyrosine hydroxylase in olfactory bulb dopaminergic neurons. Methods 8, 3658-3669.

Merkle, F. T., Mirzadeh, Z., and Alvarez-buylla, A. (2007). Mosaic organization of neural stem cells in the adult brain. Science 317, 381-384. doi: 10.1126/science. 1144914

Nadi, N. S., Head, R., Grillo, M., Hempstead, J., Grannot-Reisfeld, N., and Margolis, F. L. (1981). Chemical deafferentation of the olfactory bulb: plasticity of the levels of tyrosine hydroxylase, dopamine and norepinephrine. Brain Res. 213, 365-377. doi: 10.1016/0006-8993(81)90241-9

Ninkovic, J., Pinto, L., Petricca, S., Lepier, A., Sun, J., Rieger, M. A., et al. (2010). The transcription factor Pax6 regulates survival of dopaminergic olfactory bulb neurons via crystallin aA. Neuron 68, 682-694. doi: 10.1016/j.neuron.2010.09.030

Parrish-Aungst, S., Kiyokage, E., Szabo, G., Yanagawa, Y., Shipley, M. T., and Puche, A. C. (2011). Sensory experience selectively regulates transmitter synthesis enzymes in interglomerular circuits. Brain Res. 1382, 70-76. doi: 10.1016/j.brainres.2011.01.068

Parrish-Aungst, S., Shipley, M. T., Erdelyi, F., Szabo, G., and Puche, A. C. (2007). Quantitative analysis of neuronal diversity in the mouse olfactory bulb. J. Comp. Neurol. 501, 825-836. doi: 10.1002/cne.21205

Pavlis, M., Feretti, C., Levy, A., Gupta, N., and Linster, C. (2006). (L)-DOPA improves odor discrimination learning in rats. Physiol. Behav. 87, 109-113. doi: 10.1016/j.physbeh.2005.09.011

Pignatelli, A., Ackman, J. B., Vigetti, D., Beltrami, A. P., Zucchini, S., and Belluzzi, O. (2009). A potential reservoir of immature dopaminergic replacement neurons in the adult mammalian olfactory bulb. Pflugers Arch. Eur. J. Physiol. 457, 899-915. doi: 10.1007/s00424-008-0535-0

Pignatelli, A., Borin, M., Fogli Iseppe, A., Gambardella, C., and Belluzzi, O. (2013). The h-current in periglomerular dopaminergic neurons of the mouse olfactory bulb. PLoS ONE 8:e56571. doi: 10.1371/journal.pone.0056571

Pignatelli, A., Kobayashi, K., Okano, H., and Belluzzi, O. (2005). Functional properties of dopaminergic neurones in the mouse olfactory bulb. J. Physiol. 564, 501-514. doi: 10.1113/jphysiol.2005.084632

Pinching, A. J., and Powell, T. P. (1971). The neuron types of the glomerular layer of the olfactory bulb. J. Cell Sci. 9, 305-345.

Rochefort, C., Gheusi, G., Vincent, J.-D., and Lledo, P.-M. (2002). Enriched odor exposure increases the number of newborn neurons in the adult olfactory bulb and improves odor memory. J. Neurosci. 22, 2679-2689.

Saino-Saito, S., Cave, J. W., Akiba, Y., Sasaki, H., Goto, K., Kobayashi, K., et al. (2007). ER81 and CaMKIV identify anatomically and phenotypically defined 
subsets of mouse olfactory bulb interneurons. J. Comp. Neurol. 502, 485-496. doi: $10.1002 /$ cne. 21293

Saino-Saito, S., Sasaki, H., Volpe, B. T., Kobayashi, K., Berlin, R., and Baker, H. (2004). Differentiation of the dopaminergic phenotype in the olfactory system of neonatal and adult mice. J. Comp. Neurol. 479, 389-398. doi: $10.1002 /$ cne. 20320

Sawada, M., Kaneko, N., Inada, H., Wake, H., Kato, Y., Yanagawa, Y., et al. (2011). Sensory input regulates spatial and subtype-specific patterns of neuronal turnover in the adult olfactory bulb. J. Neurosci. 31, 11587-11596. doi: 10.1523/JNEUROSCI.0614-11.2011

Sawamoto, K., Nakao, N., Kobayashi, K., Matsushita, N., Takahashi, H., Kakishita, K., et al. (2001). Visualization, direct isolation, and transplantation of midbrain dopaminergic neurons. Proc. Natl. Acad. Sci. U.S.A. 98, 6423-6428. doi: 10.1073/pnas.111152398

Serguera, C., Triaca, V., Kelly-Barrett, J., Banchaabouchi, M. A., and Minichiello, L. (2008). Increased dopamine after mating impairs olfaction and prevents odor interference with pregnancy. Nat. Neurosci. 11, 949-956. doi: 10.1038/ nn. 2154

Sternson, S. M., and Roth, B. L. (2014). Chemogenetic tools to interrogate brain functions. Annu. Rev. Neurosci. 37, 387-407. doi: 10.1146/annurev-neuro071013-014048

Tillerson, J. L., Caudle, W. M., Parent, J. M., Gong, C., Schallert, T., and Miller, G. W. (2006). Olfactory discrimination deficits in mice lacking the dopamine transporter or the D2 dopamine receptor. Behav. Brain Res. 172, 97-105. doi: 10.1016/j.bbr.2006.04.025

Vergaño-Vera, E., Díaz-Guerra, E., Rodríguez-Traver, E., Méndez-Gómez, H. R., Solís, Ó., Pignatelli, J., et al. (2015). Nurr1 blocks the mitogenic effect of FGF-2 and EGF, inducing olfactory bulb neural stem cells to adopt dopaminergic and dopaminergic-GABAergic neuronal phenotypes. Dev. Neurobiol. 75, 823-841. doi: 10.1002/dneu.22251

Vergaño-Vera, E., Yusta-boyo, M. J., De Castro, F., Bernad, A., De Pablo, F., Vicario-abejón, C., et al. (2006). Generation of GABAergic and dopaminergic interneurons from endogenous embryonic olfactory bulb precursor cells. Development 133, 4367-4379. doi: 10.1242/dev. 02601

Wei, C. J., Linster, C., and Cleland, T. A. (2006). Dopamine D(2) receptor activation modulates perceived odor intensity. Behav. Neurosci. 120, 393-400. doi: 10.1037/0735-7044.120.2.393

Zhou, X., Liu, F., Tian, M., Xu, Z., Liang, Q., Wang, C., et al. (2015). Transcription factors COUP-TFI and COUP-TFII are required for the production of granule cells in the mouse olfactory bulb. Development 142, 1593-1605. doi: $10.1242 /$ dev.115279

Conflict of Interest Statement: The authors declare that the research was conducted in the absence of any commercial or financial relationships that could be construed as a potential conflict of interest.

Copyright (C) 2016 Bonzano, Bovetti, Gendusa, Peretto and De Marchis. This is an open-access article distributed under the terms of the Creative Commons Attribution License (CC BY). The use, distribution or reproduction in other forums is permitted, provided the original author(s) or licensor are credited and that the original publication in this journal is cited, in accordance with accepted academic practice. No use, distribution or reproduction is permitted which does not comply with these terms. 